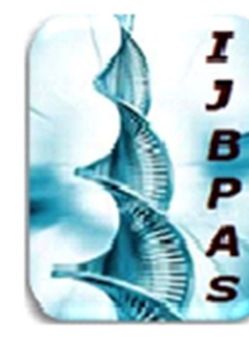

\author{
International Journal of Biology, Pharmacy \\ and Allied Sciences (IJBPAS) \\ 'A Bridge Botusen caboratory and QRendo'
}

Www.ijbpas.com

\title{
ROLE OF LAPAROSCOPIC TECHNIQUE IN SURGICAL MANAGEMENT OF ACUTE ADHESIVE SMALL INTESTINAL OBSTRUCTION
}

\section{PATEL $\mathrm{N}^{1^{*}}$, NANGARE $\mathrm{N}^{2}$ AND URVI V. WADER ${ }^{3}$}

1: Junior Resident, Department of surgery, Krishna Institute of Medical Sciences Deemed be

$$
\text { University, Karad, Maharastra (India) }
$$

2: Professor, Department of Surgery, Krishna Institute of Medical Sciences Deemed to be

$$
\text { University, Karad, Maharastra (India) }
$$

3: Senior Resident, Department of Surgery, Krishna Institute of Medical Sciences Deemed to be University, Karad, Maharastra (India)

*Corresponding Author: Dr. Nishith G. Patel: E Mail: nishith.patel5902@gmail.com

Received $12^{\text {th }}$ July 2021; Revised $14^{\text {th }}$ Aug. 2021; Accepted $27^{\text {th }}$ Oct. 2021; Available online $15^{\text {th }}$ Feb. 2022

\section{https://doi.org/10.31032/IJBPAS/2022/11.2.1011}

\section{ABSTRACT}

\section{Background}

Post abdominal surgery adhesions form a total of $65 \%$ of the total acute small bowel obstruction cases. Open technique is equivalent to the previously established techniques for adhesiolysis, the laparoscopic techniques have become better-known.

\section{Methods}

A retrospective study was performed from previously established records from reports of sufferers who were managed operatively for adhesive small bowel obstruction from January 2018 to May 2021. After surgery effects comparing open against laparoscopic technique were looked into. An intention-to-deal with evaluation changed into performed. The motive of this have a look at changed into to definitively infer if laparoscpic technique of bowel adhesiolysis trumped open technique.

\section{Results}


250 patients operated on for adhesive small intestinal obstruction have been included. 175 $(70 \%)$ and $75(30 \%)$ sufferers, respectively, were operated by open and laparoscopic techniques. The rate of conversion was found to be $38.5 \%$. Patients who underwent laparoscopy were more youthful $\mathrm{p}<0.001$, and had not many bowel surgery $\mathrm{p}=0.001$, A smaller ASA grade $p<0.001$ and uncomplicated adhesions were noted $p=0.001$. Open technique took longer to operate $p=0.0045$. Laparoscopic adhesiolysis was cheaper $(42 \%$ vs. $68 \%, p<0.00$, lessened death rate $\mathrm{p}=0.027$, early breaking of nil per oral $\mathrm{p}<0.001$ and shorter indoor stay $\mathrm{p}<0.001$. Specific evaluation of patients with a single band and / or internal hernia who did, now no longer required bowel resection, additionally were found with few problems, in early breaking of nil per oral and extra hospitalization. The open technique was found to have more complications as against the laparoscopic variant (odds ratio $=2.9 ; 95 \%$ CI $1.1-7.3 ; \mathrm{p}=0.03)$.

\section{Conclusions}

Laparoscopic method of bowel adhesiolysis has superior final results over open technique Laparoscopic control of adhesiolysis in small bowel obstruction is viable and effective. The laparoscopy technique improves effects and recovery.

\section{INTRODUCTION}

Post op bowel adhesions is the commonest cause of acute bowel obstruction, accounting for $65 \%$ of all cases. In these cases $48 \%$ of the patients need operative management [1]. In open operative management of bowel adhesions morbidity and mortality remain high in comparison to laproscopic approach, with rates of approximately $15-40$ and 3\%, respectively $[2,3,4,5,6]$. The laparoscopic approach has shown superiority in both emergency and elective situations. It has proven less ill health, less postsurgery pain and lesser indoor time [1, 7]. However, the open approach is still considered the standard surgical approach in most centers [1].
The main issues associated with the laparoscopic approach for adhesive obstruction of the small bowel are: the risk of intestinal trauma, the difficulty of intraoperative manipulation of the intestinal loops, the difficult etiology of the obstruction, along with high expense of surgery [8].

The goal of this research is to compare the impact of the laparoscopic technique on postsurgery benefits in our patients successively managed surgically for adhesive bowel obstruction.

\section{METHODS}

A retrospective study was carried out utilising information from older researches 
with patients who had laparoscopic or open surgery for adhesive bowel obstruction (including internal hernias). Only emergency operations were considered for analysis. Ryle's tude insertion was done in suspected patients of small bowel obstruction A dye based radiological evaluation was done to distinguish conservative patients from patients who need operative management. The patients who were unable to pass the radio-opaque dye past their colon within 24 hours, they were deemed to be considered operative. Non adhesive bowel obstruction patiens are excludecd from the study.

The variables evaluated were: a) before surgery: age, gender, anaesthesia score, total previous abdominal surgeries, anterior abdominal mesh; b) during surgery: experience of the surgeon in modern laparoscopy, approach, conversion, surgery duration, intraoperative discoveries, intraoperative injury; c) after surgery: ill health, death rate, breaking NBM, revision surgery, duration of in-patient stay, rehospitalisation and quality results.

Surgical approach to each patient was under the judgement of each individual surgeon considering various clinical parameters. These include hemodynamic uncertainty, query bowel ischemia, certainly hostile bowel and lung complications were considered not fit for to the laparoscopic approach.

\section{RESULTS}

A total of 250 patients underwent surgical operation for Adhesive small bowel obstrtion, 75 (30\%) by laparoscopy and $175(70 \%)$ by laparotomy approach. Patients who underwent laparotomy were old, had history of more abdominal operative procedures, had greater ASA score.

Although about $48 \%$ of all the Adhesive small bowel obstruction were caused by complex adhesions, more complex adhesions were operated by the open approach compared to the laparoscopic approach.

25 patients $(38.5 \%)$ were switched to open technique since technique was found to be tough in 15 , necessity for widespread intestine resection in 4; intestinal injury in 3; and trocar-inducedage in 3.

$18(7 \%)$ patients incurred mortality. No major differences were found. But death rate was more in patients with complicated adhesions (8.5\% vs 4\%; $\mathrm{p}=$ $0.090)$ and intestinal resection (11\% vs $5.4 \% ; \mathrm{p}=0.212)$. The average age of the patients who incurred mortality was 75 years, 7 patients had high anaesthesia score of IV, 6 had complicated adhesions and 5 needed intestinal resection. 


\section{DISCUSSION}

Our research shows that the laparoscopy is better for management of small bowel obstruction adhesions due to better postsurgery results, lesser ill health, earlier breaking of NBM and less in-patient stay. Total earlier bowel surgeries, their type, the degree of peritoneal damage are important parmaeters which affect the presentation of adhesions. Laparoscopic approach had superior outcome with low re-admissions and repeat need for operations. The open approach in the management of adhesive small intestine obstruction is in itself a factor in the development of new adhesive small intestine obstruction.

The complications of laparaoscopic approach are associated with difficulty in manipulation bowel and peritoneum and the subsequent trauma. In a review of 20 studies including 1,060 cases of adhesive small bowel obstruction operated on laparoscopically, the rate of intraoperative enterotomy was $7 \%$ while that of missed perforation was $1 \%$, Laparoscpoic approach had fewer incidence of perforations, perhaps because of more number of complex adhesions in open surgery $(59 \%$ vs. $31 \%)$ or the low conversion threshold.
Our report says that laparoscopy is safer since it does not increase the risk of intraoperative enterotomy.

In this study, any widening of the incision was considered a conversion, so the conversion rate of $37 \%$ is within published limits. The success of laparoscopy depends on: early treatment, diameter of bowel loops $<4.5 \mathrm{~cm}$, maximum 2 previous operations, no previous midline laparotomy, single band adhesions and experience. The surgeons's laparoscopic skills are an important factor for favourable outcomes as pointed out in the study.an important point to be notes is that the morbidity and mortality rates increased post conversion. As pointed out earlier it may be due to the extensive complex adhesions in patients which need conversion rather than the conversion itself.

\section{CONCLUSIONS}

Laparoscopic method in bowel adhesiolysis had superior outcome in managing small bowel adhesion and internal hernias.in parameters such as short in door stay, earlier breaking of nil per oral, reduce morbidity.

\section{Acknowledgement}

I am thankful to Mrs Rupali Salunkhe for secretariat help, Institute of medical sciences Deemed To Be University, Karad, Maharashtra (India).

\section{REFERENCE}


[1] Mancini GJ, Petroski GF, Lin WC, Sporn E, Miedema BW, Thaler K, Nationwide impact of laparoscopic lysis of adhesions in the management of intestinal obstruction in the US, Journal of the American College of Surgeons, 207(4), 2008, 520-6.

[2] O'Connor DB, Winter DC, The role of laparoscopy in the management of acute small-bowel obstruction: a review of over 2,000 cases, Surgical endoscopy, 26(1), 2012, 12-7.

[3] Khaikin M, Schneidereit N, Cera S, Sands D, Efron J, Weiss EG, et al, Laparoscopic vs, open surgery for acute adhesive small-bowel obstruction: patients' outcome and cost-effectiveness, Surgical endoscopy, 21(5), 2007, 742-6.

[4] Li MZ, Lian L, Xiao LB, Wu WH, He YL, Song XM, Laparoscopic versus open adhesiolysis in patients with adhesive small bowel obstruction: a systematic review and meta-analysis, The American journal of surgery, 204(5), 2012, 779-86.

[5] Poves I, Valverde ES, Companyó SP, Dorcaratto D, Membrilla E, Pons MJ, et al, Results of a laparoscopic approach for the treatment of acute small bowel obstruction due to adhesions and internal hernias, Cirugía Española (English Edition), 92(5), 2014, 33640.

[6] Ghosheh B, Salameh JR, Laparoscopic approach to acute small bowel obstruction: review of 1061 cases, Surgical endoscopy, 21(11), 2007, 1945-9.

[7] Wiggins T, Markar SR, Harris A, Laparoscopic adhesiolysis for acute small bowel obstruction: systematic review and pooled analysis, Surgical endoscopy, 29(12), 2015, $3432-42$.

[8] Suter M, Zermatten P, Halkic N, Martinet $\mathrm{O}$, Bettschart $\mathrm{V}$, Laparoscopic management of mechanical small bowel obstruction, Surgical endoscopy, 14(5), 2000, 478-83. 